\title{
Agama dalam Tentukur Antropologi Simbolik Clifford Geertz
}

\author{
Religion in the Perspective of Clifford Geert's Symbolical Anthropology
}

YUSRI MOHAMAD RAMLI ${ }^{1}$

\begin{abstract}
Clifford Geertz can be regarded as one of the most influential figures in religious studies, particularly in the field of anthropology. His unique symbolic anthropology approach had attracted researchers because of his emphasis on deductive reasoning in explaining the meaning of religion and in viewing cultural values that exist in religion. Research based on the content analysis of his works found that Clifford Geertz thought very strongly influenced by Ibn Khaldun as both of them emphasize on the practical reality of religious phenomena in the society. These symbols are then making a cultural system of what we call religion.
\end{abstract}

Keywords: Cilfford Geertz, culture, religious anthropology, symbolism.

Perbahasan dalam mengungkap pengertian istilah agama dalam kalangan pengkaji memperlihatkan kepelbagaian ruang lingkup dan keluasan cakupan yang boleh diambilkira dalam memahami agama melalui pendekatan yang berbeza-beza. Pandangan para sarjana mengenai definisi agama merangkumi sistem kepercayaan, cara hidup, kerohanian dan sebagainya. Clifford Geertz yang dilihat sebagai salah satu nama besar dalam bidang antropologi agama telah memberikan satu pengertian yang unik, bukan sahaja menjelaskan maksud agama itu sendiri, bahkan mendatangkan satu paradigma baru dalam melihat dan memahami agama itu sendiri. Melalui pendekatan antropologi simboliknya, Geertz melihat agama sebagai satu sistem kebudayaan yang ditandai dengan simbol-simbol yang menonjolkan citra keagamaan sesebuah masyarakat beragama.

Walaupun Geertz telah meninggal dunia, namun pemikiran beliau masih dianggap penting dan relevan khususnya dalam mengingatkan kepentingan unsur praktikal dalam realiti penganut sesuatu kepercayaan agar dapat memahami agama dan segala isu berkaitannya dengan lebih jelas dan komprehensif. Melalui kajian kepustakaan terhadap karya-karya beliau khususnya Islam Observed: Religious Development in Morocco and Indonesia yang menjadi asas pemaparan pemikiran beliau, artikel ini menyelongkar maksud agama dalam kerangka antroplogi simbolik Clifford Geertz.

\section{Latar Belakang Clifford Geertz}

Clifford James Geertz lahir di San Francisco, California, Amerika Syarikat pada 23 Ogos 1926. Geertz telah menjadi editor akhbar dan majalah sekolah tingginya dan menjangkakan dirinya suatu hari nanti akan menjadi seorang wartawan pada siang hari dan seorang penulis pada malam hari. Setelah berkhidmat dalam angkatan tentera laut Amerika Syarikat dalam Perang Dunia ke-2 dari tahun 1943 hingga 1945, beliau melanjutkan pelajaran di Kolej Antioch, Ohio di mana beliau mengkhususkan major dalam bahasa Inggeris bagi

${ }^{1}$ Yusri Mohamad Ramli, Ph.D., Lecturer at Department of Theology and Philosophy, Faculty of Islamic Studies, Universiti Kebangsaan Malaysia, 43600 BANGI, Selangor, Malaysia, email: yusri_mr@ukm.edu.my 
memperoleh sarjanamuda. Beliau kemudiannya menukar bidang kepada falsafah dan antropologi di atas cadangan gurunya yang dianggap hebat dan begitu mempengaruhinya iaitu George Geiger. Setelah memperolehi ijazah sarjanamuda pada tahun 1950, Geertz bersama-sama isterinya, Hildred Geertz memasuki Harvard untuk mempelajari bidang hubungan sosial kerana berminat untuk menyambung ke peringkat sarjana dalam bidang antropologi (Banton 1969: 175; Pick 2012; Thirteen 2012). Setelah belajar selama dua tahun, beliau mula menjalankan projek pertamanya di Rimrock yang terletak di barat daya Amerika Syarikat. Ketika di sana, beliau mengkaji tentang kemarau dan kesan alkohol terhadap empat budaya di dalam wilayah tersebut. Setelah tamat kajiannya, beliau mula menulis artikel profesionalnya yang pertama (EMuseum 2012).

Setelah kajian berakhir, beliau diberi peluang untuk pergi ke Indonesia bersama isterinya. Ketika di Indonesia, beliau mengkaji tentang agama, manakala isterinya pula mengkaji tentang keluarga dan hubungan kekeluargaan. Mereka kemudiannya membukukan hasil kajian mengenai kekeluargaan ini dengan judul Kinship in Bali yang diterbitkan oleh University of Chicago Press, Chicago pada tahun 1975. Apabila Geertz kembali dari Indonesia, beliau menulis buku pertamanya, Agricultural Involution. Buku ini menerangkan dua jenis pertanian yang utama di Indonesia iaitu swidden dan sawah padi dan tentang penempatan geografi mereka. Buku ini turut menerangkan mengenai perkembangan sejarah pertanian Indonesia dengan mengembangkan hipotesis bahawa bentuk-bentuk pertanian yang wujud adalah berkembang disebabkan perubahan yang berlaku. Sejak itu, Geertz telah menerbitkan lebih sedozen buah buku (EMuseum 2012).

Geertz kemudiannya memperolehi Ph.D di Harvard pada tahun 1956. Beliau seterusnya menjadi instruktor dalam bidang antropologi di Universiti Harvard dari tahun 1956 hingga 1957 dan menjadi Penyelidik Bersekutu di Center for International Studies di the Massachusetts Institute of Technology pada tahun 1957. Beliau kemudiannya dilantik menjadi Felo di Center for Advanced Study in the Behavioral Sciences di Universiti Stanford di Palo Alto (1958-1959) di samping menjawat jawatan sebagai Penolong Profesor dalam bidang Antropologi di Universiti California, Berkeley (1958-1960). Selepas itu beliau dilantik sebagai Penolong Profesor Antropologi di Universiti Chicago (1960-1962) dan kemudiannya menjadi Profesor Madya (1962-1964) serta Profesor (1964-1970) di universiti tersebut (Banton 1969: 175; Thirteen 2012).

Geertz sejak tahun 1970, menjadi Profesor Sains Sosial di Institute for Advanced Study (IAS) di Princeton, New Jersey hingga tahun 2000 dan seterusnya sehingga akhir hayatnya menjadi Profesor Emeritus Sains Sosial. Beliau juga pernah menjadi profesor jemputan dalam bidang kajian Timur di Universiti Oxford antara tahun 1978-1979. Ideaidea beliau menarik minat para ahli antropologi dan juga bidang-bidang lain. Karyakaryanya dipersembahkan kepada masyarakat dengan pandangannya tentang budayabudaya lain yang lebih bersifat realistik dan kurang bersifat platonik (teoritikal). Matlamat pengkajian dan penulisannya tidak pernah diarahkan untuk mengekalkan metodologi tertentu, tetapi ditumpukan untuk menyusun nada atau mood atau agenda yang manusia mampu bertindakbalas terhadapnya ataupun sebaliknya (EMuseum 2012).

Clifford Geertz dianggap sebagai salah seorang pakar sains sosial yang terpenting pada masa kini. Beliau telah menjalankan pelbagai kajian ethnografi yang bernilai tinggi di Asia Tenggara dan Utara Afrika. Beliau turut menyumbang banyak teori sosial dan budaya dan melebarkan pengaruhnya dalam mengubah konsep antropologi kepada suatu keperihatinan dalam kerangka makna bahawa pelbagai manusia hidup di luar dari kehidupan mereka. Beliau banyak memfokuskan kajiannya terhadap agama, khususnya Islam, juga tentang perniagaan bazar, pembangunan ekonomi, stuktur politik tradisional, 
serta kehidupan keluarga dan kampung di samping perbezaan etnik dan implikasinya di dalam dunia moden (Roebuckclasses 2012).

Antara karya Geertz ialah (Roebuckclasses 2012; Shop4Author 2012):

- $\quad$ The Development of Javanese Economy: A Socio-Cultural Approach (1956).

- $\quad$ The Religion of Java (1960). Karya ini telah diterjemahkan ke dalam bahasa Melayu Indonesia oleh Aswab Mahasin dengan judul Abangan, Santri, Priyayi dalam Masyarakat Jawa (1981).

- $\quad$ Peddlers and Princes: Social Development and Economic Change in Two Indonesian Towns (Comparative Studies of New Nations) (1963).

- Agricultural Involution: the Processes of Ecological Change in Indonesia (1963). Buku ini telah diterjemahkan ke dalam bahasa Melayu (Indonesia) dengan judul, Involusi Pertanian: Proses Perubahan Ekologi di Indonesia, Jakarta Barat.

- $\quad$ The Social History of an Indonesian/Javanese Town (1965).

- Islam Observed: Religious Development in Morocco and Indonesia (1968).

- $\quad$ The Interpretation of Cultures (1973).

- $\quad$ Myth, Symbol, and Culture (1974).

- $\quad$ Negara: the Theater State in Nineteenth-Century Bali (1980).

- $\quad$ Local Knowledge: Further Essays in Interpretive Anthropology (1983).

- $\quad$ Works and Lives: the Anthropologist as Author (1988).

- After the Fact: Two Countries, Four Decades, One Anthropologist (The Jerusalem-Harvard Lectures) (1995).

- $\quad$ Available Light: Anthropological Reflections on Philosophical Topics.

- $\quad$ The Fate of 'Culture': Geertz and Beyond (Representations Books).

- Geiger at Antioch (George Geiger, Professor at Antioch College): an Article from the Antioch Review.

- $\quad$ New Views of the Nature Man.

Beliau turut menulis banyak artikel khususnya di dalam buku-buku dan jurnaljurnal antropologi seperti:

- $\quad$ Ethos, World-view and the Analysis of Sacred Symbols (1958).

- $\quad$ The Growth of Culture and the Evolution of Mind (1962).

- $\quad$ Ideology as a Cultural System (1964).

- $\quad$ Internal Conversion in Contemporary Bali (1964a).

Geertz telah mendapat beberapa anugerah penghormatan. Antaranya ialah National Book Critics Circle Prize dalam penulisan kritis pada tahun 1989 bagi karyanya, Works and Lives. Beliau juga adalah ahli lembaga penasihat jurnal the Antioch Review, di samping menjadi penulis penyumbang dalam the New York Review of Books. Beliau juga telah mendapat ijazah kehormat undang-undang (L.H.D.) daripada Bates College pada tahun 1980 (Thirteen 2012). Geertz telah meninggal dunia pada 30 Oktober 2006 di Philadelphia akibat komplikasi setelah pembedahan hatinya. Untuk melihat lebih lanjut mengenai Clifford Geertz, Fred Inglis (1999) dalam memperkenalkan tokoh antropologi agama ini telah menyebutkan secara terperinci mengenai latar belakang dan pemikiran beliau di dalam autobiografi yang ditulisnya berjudul Clifford Geertz: Culture, Custom, and Ethics.

\section{Pendekatan Antropologi Simbolik}

https://doi.org/10.24035/ijit.1.2012.008 
Dalam memahami pemikiran antropologi simbolik Clifford Geertz, adalah penting untuk melihat karya beliau yang berjudul Islam Observed: Religious Development in Morocco and Indonesia. Ia telah diterbitkan untuk pertama kalinya pada tahun 1968 serta diulang cetak beberapa kali. Tulisan ini dianggap sebagai antara karya terpenting bagi beliau dan juga bagi bidang antropologi sehingga menjadi rujukan utama di universiti-universiti Eropah, Amerika dan Asia. Karya Geertz ini sebenarnya merupakan koleksi syarahan beliau yang disampaikan di bawah pembiayaan Dwight Harrington Terry Foundation pada tahun 1967 berdasarkan kepada pengalaman dan kajian yang telah beliau jalankan di Maghribi dan Indonesia. Buku ini telah diterjemahkan ke dalam pelbagai bahasa termasuklah Perancis dan Indonesia (Geertz 1982; Shop4Author 2006). Geertz (1968) di dalam Islam Observed memulakan hujahnya dengan menggariskan isu dan permasalahan secara konsepsi dan menyediakan satu pandangan umum mengenai dua negara kajiannya, Maghribi (Morocco) dan Indonesia. Beliau kemudiannya menemukan evolusi yang berlaku dalam gaya agama yang diwarisi secara tradisi kesan daripada proses sejarah yang unik yang menghasilkan iklim keagamaan yang berbeza antara Maghribi dan Indonesia. Di Maghribi, konsep kehidupan Islam terangkum dalam makna aktivisme, moralisme, dan individualiti. Sedangkan di Indonesia pula tertumpu pada estetisisme dan personaliti yang radikal. Bagi mencapai maksud penting dalam perkembangan yang menarik ini, Geertz membuat pemerhatian secara teoritikal tentang peranan sosial terhadap agama.

Banyak daripada idea-idea yang dikemukakan oleh Geertz di dalam teks ini telah diperkembangkan secara lebih sistematik dan terperinci di dalam beberapa tulisan beliau sendiri seperti Ethos, World-View and the Analysis of Sacred Symbol (Geertz 1958), The Growth of Culture and the Evolution of Mind (Geertz 1962), Ideology as a Cultural System (Geertz 1964), The Social History of an Indonesian Town (Geertz 1965), Religion as a Cultural System (Geertz 1966), Person, Time and Conduct in Bali (Gertz 1966a), dan juga The Impact of the Concept of Culture on the Concept of Man (Geertz 1966b).

Beliau merupakan pengkaji dan penulis yang prolifik dalam arena antropologi. Nama dan pengaruh beliau meningkat naik dengan pelbagai penyelidikan beliau tentang sosio budaya di Indonesia. Sejak kajian pertama beliau iaitu mengenai kehidupan beragama dan kesannya dalam corak hubungan sosial di kalangan masyarakat Jawa, beliau mula memperlihatkan kecenderungan dan pengaruh untuk mengkaji keadaan sosial, kebudayaan, dan politik di Indonesia (Taufik 1982: i-xvi). Pendekatan yang digunakan oleh Geertz amat unik dan tidak seperti antropologis konvensional yang bersifat deskriptif. Pengkajian Geertz bersifat empirikal dan tidak bertitik tolak dari sesuatu teori. Subjek kajianlah yang menjadi nadi kepada hasil dan rumusan kajian yang beliau jalankan. Masyarakat yang menjadi bahan kajian beliau dianalisis melalui corak hubungan sosial dan kecenderungan budaya yang diperhatikan dalam amalan masyarakat tersebut. Malah beliau turut melihat kepada kemungkinan daya kemampuan masyarakat tersebut untuk menghadapi perubahan budaya. Pendekatan sebegini dilihat sangat praktikal untuk memahami proses perubahan sosial yang terjadi.

Kajian-kajian Geertz memperlihatkan kemampuan beliau dalam menarik perhatian pembaca dan menonjolkan kewibawaannya dalam merungkai persoalan-persoalan yang diajukan terhadap sasaran kajiannya. Oleh itu, tidak hairanlah pengaruh beliau samada pro dan kontra melebar dengan meluas di dalam pelbagai lapangan ilmu. Geertz tidak cuba menghasilkan teori-teori baru yang boleh dipakai untuk menilai gelagat-gelagat sosial dan tidak juga terikat dengan isu-isu khusus dan juz'i seperti yang biasa dilakukan oleh para pengkaji. Beliau sebaliknya cuba mengaitkan isu yang khusus yang didapatinya melalui kajian empirikal dengan isu yang lebih umum. Ini bukan bermakna Geertz mengumumkan 
perkara yang khusus, tetapi mencari apakah yang dapat diberikan oleh hal yang khusus kepada hal yang lebih besar dan kompleks. Dalam erti kata lain, pendekatan Geertz ini cuba mendapatkan pemahaman yang lebih komprehensif terhadap gejala-gejala yang ditelitinya. Kecenderungan seperti ini berpaksi pada pengertian Geertz tentang kebudayaan sebagai sasaran kajian dan juga bagaimana menurutnya sesuatu kajian antropologi itu harus dilakukan (Taufik 1982: i-xvi). Bagi Geertz, kebudayaan itu berkait rapat dengan simbol atau lambang. Dengan simbol inilah katanya, manusia saling menyampaikan fikiran, perasaan dan berkomunikasi. Kebudayaan tidak terjadi dengan kebiasaan, tetapi berdasarkan tafsiran atau interpretasi sesebuah masyarakat terhadap sesuatu pengalaman.

\section{Dari Mana Datangnya Agama?}

Clifford Geertz (1968) di dalam Islam Observed menjelaskan mengenai perjuangan dan metodologi masyarakat di kedua-dua negara dalam mempertahankan kepercayaan dan amalan agama mereka. Beliau juga mengkritik isu-isu dan pandangan yang dibangkitkan oleh ahli-ahli sosiologi dan politik. Beliau juga banyak menggunakan pendekatan perbandingan secara tipologi yang begitu teknikal dan begitu cenderung untuk menggabungkan antara metod dan teori walaupun sebenarnya beliau lebih banyak mengutamakan aspek praktikal sehingga mengabaikan konsep-konsep keagamaan. Geertz cuba menjelaskan pandangan beliau mengenai asal-usul agama di dalam sesebuah masyarakat. Beliau berpendapat bahawa ciri utama dari kepercayaan agama berbanding dengan kepercayaan yang lain seperti ideologi, falsafah, ilmu, atau akal ialah bahawa kepercayaan agama itu bukan suatu rumusan dari pengalaman, bahkan pengalaman itu lahir dari kepercayaan agama. Para penganut agama mendapat agama itu bukan secara induktif, tetapi secara deduktif.

Geertz gemar membangkitkan pandangan ahli sosiologi dan politik dan mengkritik idea-idea mereka yang dianggap tidak realistik dan tidak praktikal. Antaranya ialah pendapat Alisdair MacIntyre (1957: 167-211), Profesor Penyelidik Senior bidang Falsafah, Jabatan Falsafah, Universiti Notre Dame dan bekas pensyarah falsafah agama di Universiti Manchester yang mengatakan bahawa kepercayaan-kepercayaan merupakan cahaya yang dipancarkan kepada kehidupan manusia dari sesuatu di luarnya. Geertz (1968) menyanggah pandangan ini dengan menegaskan bahawa ahli sosiologi dan juga antropologi secara umumnya tidak begitu berkenan dengan rumusan seperti ini, bukan kebanyakan mereka tidak beragama (termasuk Geertz sendiri), tetapi kerana ia menyimpang dari jalur empirisme dalam menjelaskan cara kepercayaan agama dizahirkan kepada para penganut agama. Pendekatan empirisme atau sains positif menitikberatkan pengalaman dan ujikaji sebagi punca sesuatu kebenaran. Lantaran itulah Geertz (1969: 1-46) mentafsirkan agama itu sebagai apa yang dipercayai dan diamalkan oleh masyarakat itu secara realitinya dan bukannya berasaskan kepada konsep-konsep agama itu sendiri. Maka dengan itulah agama itu sendiri dianggap sebagai suatu sistem budaya.

Persoalan yang paling penting dalam pengkajian ini ialah apakah sebabnya masyarakat itu percaya dengan kepercayaan mereka itu? Dari manakah asalnya kepercayaan mereka itu? Menurut Geertz (1968), adalah jelas bahawa kepercayaan itu timbul dari pengaruh sosial dan simbol-simbol agama. Seseorang itu lahir ke dunia tidak menciptakan agama dan budaya untuk dipercayai dan diamalkannya, melainkan agama atau budaya itu sememangnya telah diterima oleh masyarakat sebagai satu agama dan budaya. Begitulah halnya seseorang itu tidak perlu mencipta bahasa untuk mula bertutur. Jadi agama itu menurut Geertz (1968) walaupun merupakan suatu pilihan yang bebas, bukannya lahir dari diri seseorang tetapi diambil dari amalan masyarakat dan simbol- 
simbol agama yang telah wujud. Simbol-simbol agama dan amalan inilah yang mewujudkan kepercayaan di dalam sesebuah masyarakat. Ini termasuklah pembacaan-pembacaan doa, zikir, kepatuhan kepada sultan atau pemimpin, dan amalan-amalan keagamaan yang akhirnya membentuk peribadi dan kepercayaan seseorang itu. Keterikatan sesebuah masyarakat dengan simbol-simbol keagamaan menjadi mekanisme utama bagi mereka untuk menerima sesuatu kepercayaan itu.

Penerangan mengenai sistem-sistem simbol ini boleh dilihat di dalam bukunya, The Religion of Java (1960). Di dalam buku tersebut, Geertz menjelaskan bagaimanakah hubungan antara struktur sosial yang ada dalam suatu masyarakat dengan penyusunan dan kewujudan simbol-simbol dan juga bagaimanakah anggota masyarakat mewujudkan integrasi dan disintegrasi dengan simbol-simbol tersebut. Geertz umumnya melihat agama sebagai suatu sistem kebudayaan. Kebudayaan tidak didefinisikan sebagai pola kelakuan tetapi sebagai pola bagi kelakuan iaitu yang terbina atas rangkaian aturan-aturan dan petunjuk yang digunakan oleh manusia untuk mengatur tingkah laku.

\section{Kenapa Manusia Beragama?}

Geertz (1968) mengajukan pertanyaan, apakah sebabnya masyarakat itu dipengaruhi oleh simbol-simbol tersebut? Apakah sebabnya masyarakat mengamalkan amalan-amalan tersebut? Apakah juga sebabnya amalan-amalan tersebut mempunyai pengaruh dan kesan terhadap masyarakat? Geertz memberi jawapan bahawa:

- Dari segi psikologinya ia merupakan suatu keinginan dan keperluan individu untuk menguatkan harapannya dari sesuatu yang dianggapnya berkuasa yang mampu memberikan harapan dan kasih sayang.

- Manakala dari segi sosialnya, tekanan dalam masyarakat bukan industri atau pertanian adalah sangat besar yang akhirnya menambahkan lagi keimanan, kepercayaan dan harapan mereka. Walau bagaimanapun amat sukar untuk menentukan adakah masyarakat beriman kerana kedua-dua faktor itu, atau adakah kerana dorongan batin yang ikhlas yang ingin mencari hidayah. Namun yang pastinya menurut beliau, kedua-dua faktor ini tidak boleh dinafikan peranannya.

- Selain faktor psikologi dan sosial, terdapat juga faktor dari sudut budaya yang timbul dari perasaan bahawa akal tidak cukup untuk menjelaskan pengalaman yang begitu kompleks. Kehidupan manusia menjangkaui batasan rasional praktikal ini diperjelaskan oleh Max Weber sebagai 'masalah makna'. Pelbagai persoalan yang membingungkan dan melampaui kemampuan moral, emosi, dan intelek manusia tidak menemui noktah penyelesaian seperti kenapakah orang yang adil itu menderita dan orang yang zalim itu hidup bahagia? Sehinggakan seperti pepatah Jawa, "Kita menjadi kebingungan seperti kerbau melihat orkestra". Inilah menjadi sebab kata Geertz, kenapa kita memerlukan wahyu-wahyu agama supaya kehidupan manusia itu tidak bertentangan dengan akal fikiran manusia dan memberikan jawapan serta merasionalkan, melogikkan, dan mewajarkan persoalan-persoalan yang telah timbul tentang aturan yang telah dibuat oleh Allah Taala.

Geertz (1968) menyimpulkan bahawa ketiga-tiga faktor ini iaitu psikologi, sosial, dan budaya sebagai penjana yang menggerakkan manusia supaya melakukan amalanamalan agama dan menerima kepercayaan-kepercayaan agama. Beliau menjelaskan bahawa untuk mempercayai itu memang mudah. Tetapi dalam masyarakat tradisional, berlaku banyak skeptisme atau kecurigaan walaupun dalam beberapa perkara tertentu 
sahaja. Ini adalah kerana berlakunya pertentangan antara apa yang dianggap benar menurut agama dan akal (walaupun asas yang paling utama dipegang sekalipun) dengan penggunaan kuasa berlandaskan agama untuk tujuan yang tidak baik.

Geertz (1968) memetik sebuah peribahasa Maghribi, "Berwaspadalah terhadap wanita dari muka, terhadap baghal dari belakang, dan terhadap orang murabit dari segala arah". Juga kata-kata para petani di Jawa, "Pada malam hari, semua harta kami milik pencuri dan pada siang hari semua harta kami milik raja kami". Walau apapun yang masyarakat katakan mengenai al-murabitun sama ada tentang individu atau tingkahlaku, mereka tetap menerima realiti golongan ini sebagai pemimpin. Umumnya menurut beliau, faktor psikologi, sosial, dan budaya sentiasa sesuai dengan akal sehinggakan orang yang tidak percaya kepada agama itu biasanya dipanggil sebagai gila dan jarang sekali dipanggil berdosa, sama ada di Maghribi ataupun Jawa.

\section{Evolusi Beragama}

Ketenteraman keagamaan inilah yang diganggu-gugat oleh perubahan-perubahan yang berlaku tidak hanya di Maghribi dan Indonesia bahkan di seluruh dunia. Ketahanan jiwa, tekanan masyarakat, dan masalah-masalah makna tidak lagi berpadu menjadi kekuatan yang ampuh untuk menggerakkan individu untuk merealisasikan simbol-simbol agama tersebut. Simbol-simbol itu memang masih ada, begitu juga dengan upacara-upacara agamanya yang dianggap mempunyai kebenaran spiritual yang abadi. Tetapi masyarakat kini berasa sukar untuk melakukan kesemua tuntutan agama dan sukar untuk menyelaraskan realiti kehidupan dengan hakikat agama.

Menurut pengamatan Clifford Geertz (1968), proses ini walau bagaimanapun masih belum begitu berkembang di Maghribi dan Indonesia walaupun perubahan tersebut semakin pantas. Di Amerika Syarikat, walaupun ramai orang yang pergi ke gereja, namun kemampuan untuk menghayati agama Kristian terus menurun. Inilah yang menimbulkan persoalan kepada beliau bahawa bolehkah keadaan ini diterbalikkan sehingga masyarakat itu kembali berpegang dengan agama seutuhnya? Apa yang jelas, berkurangnya keyakinan agama itu adalah disebabkan hilangnya kekuatan simbol-simbol agama itu bagi masyarakat dan juga disebabkan sekularisasi pemikiran dan proses mengideologikan agama.

\section{Agama dan Sekularisasi}

Terdapat banyak sebab berlakunya sekularisasi dalam dunia moden. Tetapi dari segi sekularisasi dari segi budaya secara umumnya merupakan hasil daripada pertumbuhan pantas dari suatu pandangan budaya yang lain yang melampaui kewajaran akal (transcommonsensical) dan juga hasil kemunculan ilmu sains positif. Ilmu dan pemikiran Barat ini telah tersebar ke negara-negara Dunia Ketiga termasuk Maghribi dan Indonesia walaupun secara relatifnya hanya sedikit sahaja. Tetapi di setiap penjuru kedua-dua negara ini telah timbul suatu kesedaran bahawa pengalaman seharian manusia dapat dimasukkan dalam konteks yang lebih luas dan bermakna dengan simbol-simbol yang menggambarkan realiti menurut hukum-hukum umum yang ditetapkan secara induktif. Atau dalam erti kata lain, akal dan pengalaman itu kini menjadi suatu sumber autoriti bagi manusia dan pemberi jawapan kepada kebingungan mereka yang sebelum ini hanya berpandu kepada kepercayaan-kepercayaan agama.

Menurut Geertz (1968), pada masa kini, masyarakat dunia cenderung untuk menyimpulkan bahawa secara asasnya tidak ada konflik antara agama dan ilmu pengetahuan (sains). Kedua-duanya merupakan suatu alternatif yang melengkapi antara 
satu sama lain. Asas ini disandarkan kepada perspektif bahawa sains tidak dicampur adukkan dengan agama. Kedua-duanya diasingkan. Oleh kerana itu tidak wujudnya pertentangan secara nyata. Keadaan yang demikian adalah sama sahaja di semua negara Islam yang telah dijajah oleh kuasa-kuasa Barat termasuk Malaysia. Namun, pertumbuhan ilmu pengetahuan yang pesat telah menyebabkan kepercayaan agama menjadi goyah dan sukar untuk dipertahankan sehingga mewujudkan ketegangan antara kedua-duanya dalam cara untuk memahami dunia ini. Pertentangan ini dari hari ke hari semakin rancak dan semakin kronik.

Geertz (1968) beranggapan bahawa jika persaingan antara agama dan ilmu untuk menegakkan kebenaran masing-masing ini diberi perhatian khusus oleh kedua-dua belah pihak (agama dan ilmu), maka sejarah agama Islam dan agama-agama lain tidak akan dapat difahami. Pertentangan ini menurut beliau tidak akan menemui titik akhirnya sama sekali. Ahli-ahli agama yang diistilahkan Geertz sebagai scripturalists yakni golongan yang menuntut ilmu di Timur Tengah dan membawa pembaharuan dalam masyarakat merupakan golongan yang paling merasai ketegangan ini iaitu antara sekularisasi yang progresif dari pemikiran dunia moden dengan intisari pandangan agama. Pergeseran tersebut telah memberi tekanan ekslusif terhadap sumber-sumber agama Islam supaya ajarannya dijauhi oleh masyarakat termasuklah di Maghribi dan Indonesia, walaupun kebanyakannya tidak secara terang-terangan. Ini menyebabkan golongan ahli agama berusaha untuk mempertahankan kebenaran agama.

\section{Reformasi Agama}

Oleh yang demikian, golongan agamalah yang menjadi penggerak kepada ideologisasi agama di kedua-dua negara ini. Mereka dianggap sebagai golongan reformis. Mereka berusaha untuk menyatukan dan menyemarakkan semangat golongan nasionalisme dan neo-tradisionalisme. Ini dianggap oleh Geertz sebagai suatu kebijaksanaan bagi masyarakat Islam dalam menghadapi dunia moden sekular dan sikap ini seharusnya dicontohi oleh semua masyarakat dan budaya. Golongan ini telah memulakan suatu revolusi intelektual yang terjelma dalam konsep-konsep politik terutamanya sebelum mencapai kemerdekaan dan selepasnya. Golongan reformis ini bukan hanya mendidik pengikut-pengikut mereka, bahkan mengajar lawan mereka supaya merumuskan cita-cita agar dapat dipertahankan peradaban dan kelangsungan hidup mereka dalam menghadapi dunia moden yang mencabar. Geertz (1968) menyimpulkan bahawa terdapat dua strategi yang digunakan khususnya oleh golongan reformis ini untuk menghadapai cabaran sekularisasi yang bukan hanya dilakukan di Maghribi dan Indonesia sahaja, bahkan di seluruh dunia Islam iaitu:

- Pemisahan secara mutlak hal-hal agama dengan ilmu.

- Usaha untuk menunjukkan bahawa kitab suci al-Quran sebenarnya mengandungi segala intipati ilmu moden tersebut.

Pendekatan pertama menyimpulkan bahawa ilmu pengetahuan atau sains tidak mempunyai erti metafizik atau spiritual dan ia hanya terbatas kepada pemahaman alam sebagai sistem dunia yang berdiri secara tersendiri. Kepercayaan dan rasional dipisahkan antara satu sama lain agar kepercayaan atau agama itu tidak tercemar dan agar ilmu itu terikat dengan agama. Pendekatan yang kedua pula menafsirkan ilmu pengetahuan sebagai hanya menjelaskan apa yang sudah terkandung di dalam agama dan memperincikan lagi perspektif agama. Geertz berpendapat bahawa kedua-dua kefahaman ini seolah-olah membentuk deisme Islam atau konsep kepercayaan kepada Tuhan berasaskan rasional 
yang mana ajaran-ajaran asas Islam dilindungi dari segala penentangan dengan cara menjauhkannya dari pengalaman manusia. Ini berbeza dengan akal sekular yang dibiarkan bebas dengan penguasaan penuh terhadap dunia. Ismail al-Faruqi (1967: 231-246) mengistilahkan dua strategi golongan skriptualis atau reformis menghadapi ilmu dan sekularisasi ini sebagai pendekatan dua buku.

Dengan cara menjauhkan Islam dari sains sekular, maka manusia akan merasa yakin bahawa penemuan-penemuannya tidak akan menimbulkan masalah terhadap kepercayaan agamanya kerana kepercayaan agama sudah menerangkan mengenai penemuan-penemuan tersebut. Geertz memetik kata-kata Muhammad Abduh bahawa:

Melakukan refleksi tentang hakikat Pencipta adalah dilarang bagi akal manusia kerana kewujudan manusia dan Tuhan itu terpisah sama sekali antara satu sama lain. Akan tetapi bagi pihak yang lain, seruan Islam agar melakukan refleksi mengenai hal-hal makluk yang diciptakan tidak dihalang atau dikenakan syarat apapun. Ini kerana sudah diketahui bahawa setiap spekulasi yang baik akan menuju kepada kepercayaan kepada Tuhan sebagaimana yang telah disebutkan di dalam al-Quran (Cragg 2001: 38-39).

Geertz juga memetik kata-kata Kenneith Cragg (2001: 37): "Dogma-dogma yang dianggap suci berdampingan dengan kebebasan-kebebasan yang dianjurkan secara menyeluruh". Beliau menyimpulkan bahawa kedua-dua strategi untuk menghadapi sekularisasi pemikiran ini diaplikasikan secara berbeza di kedua-dua buah negara, Maghribi dan Indonesia. Di Indonesia yang semangnya cenderung untuk menyerap segala gaya fikiran secara sinkritisme dengan sendirinya lebih terbuka untuk menerima pernyataan bahawa ajaran Islam dan penemuan-penemuan sains tidak bercanggah malah saling melengkapi antara satu sama lain. Sedangkan di Maghribi pula, yang cenderung untuk membentuk jati agama yang sempurna dan moral yang mapan, dilihat lebih terbuka untuk memisahkan ajaran Islam daripada sebarang perkara yang mencemarkan Islam dari kehidupan sehari-hari.

Di kedua-dua negara, golongan reformis (skriptualis) sememangnya tidak sependapat dengan golongan tradisionalis, illuminasionis dan juga al-murabitun. Walau apapun, kedua-dua pihak ini tetap rakyat Maghribi ataupun Indonesia. Tetapi golongan reformis ini tidak dapat membebaskan diri daripada apa yang diistilah oleh Geertz sebagai pertentangan antara Fabianisme (sistem politik dan sosial yang bersifat konservatif, tradisional, ortodoks dan bentuk lama) dari satu peradaban dan Utopianisme (sistem politik dan sosial yang sempurna dan yang dicita-citakan, bersifat platonik dan idealistik, tetapi kurang praktikal). Sebagai contohnya kiyai (ulama) di Indonesia telah berusaha menyebarkan bahawa ilmu moden, bahkan pemikiran sekular adalah tidak lain dan tidak bukan merupakan pengungkapan dari Islam itu sendiri. Hanya caranya sahaja yang berbeza di mana pendekatan secara praktikal oleh ilmu moden membantu menjelaskan pendekatan teori yang dihurai secara mendalam dalam al-Quran. Manakala di Maghribi pula, golongan reformis berusaha untuk memulihkan ajaran Islam dari tahyul dan pemikiran yang sempit kepada apa yang diidealisasikan terhadap Islam yang sempurna di samping membebaskan kehidupan sekular dari kekangan doktrin. Oleh kerana itulah ilmu pengetahuan tidak menimbulkan ancaman kepada kepercayaan agama, kerana dari satu sudut ilmu atau sains moden itu dianggap sebahagian dari agama dan dari satu sudut yang lain ilmu itu juga dianggap bukan sebahagian dari agama.

Hasil-hasil yang telah dicapai oleh golongan reformis dalam mengideologikan Islam dalam konteks dunia moden telah digunakan dengan lebih berkesan terhadap pendekatan 
agama klasik yang sememangnya merupakan sasaran utama mereka. Walaupun golongan reformis ini telah menumbuhkan semangat nasionalisme, tetapi mereka cuba menjauhkannya dalam erti kata cuba berpegang dengan kepercayaan yang lebih kukuh di kedua-dua negara ini. Ini dilakukan supaya lebih menonjolkan nasionalisme atas agama, budaya dan tradisi sebenar mereka yang sejati dan tidak terikat dengan budaya luar yang sekular. Namun dalam menyesuaikannya dengan dunia moden, golongan reformis menggunakan strategi-strategi tersebut untuk mengideologikan agama. Malah mereka melanjutkannya dengan gerakan untuk menyemai penghayatan agama supaya masyarakat patuh kepada peraturan-peraturan agama sesempurnanya.

Geertz (1980) memberi contoh Sukarno yang cuba menghidupkan kembali negara teater sebagaimana yang pernah diamalkan semasa zaman kegemilangan kerajaan Majapahit, Mataram dan sebagainya di Jawa dengan asas nasionalisme revolusi dan juga usaha Sultan Muhammad V (al-Khamis) untuk menghidupkan kembali al-murabitun dengan asas yang sama dan nasionalisme revolusi yang sama. Usaha di Indonesia ini didasarkan kepada usaha membangkitkan suatu corak keagamaan berbentuk sekular yang meliputi segala aspek. Sekular di sini menurut Geertz bermaksud mewujudkan pemikiran yang lebih liberal dan moderat, sesuai dengan perubahan dunia. Manakala di Maghribi pula adalah didasarkan kepada usaha-usaha untuk membuat pemisahan secara radikal antara kebaikan peribadi (agama) dan kehidupan umum (sekular). Geertz (1968) menegaskan bahawa kemampuan supaya tradisi-tradisi yang sudah diperbaiki ini terus bertahan untuk masamasa seterusnya adalah bergantung kepada kemampuan pola kehidupan yang diakibatkan oleh tradisi-tradisi tersebut untuk terus hidup dan kekal dalam negara-bangsa yang separa moden dalam pertengahan kedua abad ke-20. Ini membawa kita kepada panduan untuk betindak dari simbol-simbol agama kepada pengaruh simbol-simbol tersebut terhadap perilaku manusia yang sebenarnya.

Geertz dikenali sebagai tokoh yang memecahkan kecenderungan terhadap pencarian saintifik pada tahun 1950-an dengan memperkenalkan gaya yang lebih bersifat metaforikal (kiasan) dan simbolik dalam disiplin ilmu antropologi. Pendekatan beliau ini menarik minat ramai pengkaji untuk meneliti dan mengkaji masyarakat berasaskan metod yang digunapakai oleh beliau.

Walau bagaimanapun terdapat ramai sarjana yang mengkritik beliau kerana terlalu menolak teori dan hanya mementingkan praktikal. Pendekatan ini dianggap sebagai sekular dan tidak mencerminkan hakikat agama yang sebenar. Mungkin pendekatan secara praktis ini dipengaruhi oleh pemikiran sosial Ibn Khaldun sebagaimana dijelaskan di dalam bukunya, Muqaddimah. Apapun, usaha yang dilakukan oleh Geertz dengan melarikan diri dari corak pengkajian saintifik yang biasa dilakukan oleh penyelidik menyebabkan namanya meningkat naik. Pendekatannya yang unik yang banyak menggunakan perbandingan berasaskan kehidupan realiti masyarakat menjadikan kajiannya benar-benar bernilai tinggi. Geertz melalui Islam Observed, menyajikan kepada kita suatu konteks umum dalam analisis perbandingan terhadap agama dan aplikasinya terhadap kajian tentang perkembangan Islam di dua buah negara yang berbeza: Indonesia dan Maghribi. Karya ini turut memperlihatkan kecenderungan beliau terhadap agama, ideologi, dan budaya dan bagaimana ia meluahkan pandangannya.

Dalam membandingkan amalan agama dalam dua komuniti ini, Geertz cuba untuk menentukan bagaimana dan dengan apa cara idea-idea, perlakuan, dan institusi yang tertentu dapat bertahan atau gagal bertahan dan memberi pengaruh kepada kepercayaan agama. Geertz juga merungkai persoalan bagaimanakah sensitiviti individu-individu beragama menunjukkan reaksi mereka apabila kepercayaan agama mereka mula meluntur dan apakah yang mereka lakukan apabila tradisi mereka ini mula pupus. Geertz juga turut 
memberi jawapan secara spesifik tentang apakah proses budaya dan suasana yang memberi kesan kepada reaksi-reaksi tersebut. Geert sangat kuat dipengaruhi oleh pemikiran Ibn Khaldun dan sering menukil pandangan Ibn Khaldun dalam banyak tulisan beliau. Namun, Geertz menyesuaikan pemikiran Ibn Khaldun dengan kupasan yang lebih dinamik dan progresif sehingga seolah-olah ia dilihat sebagai pemikiran asli Geertz sendiri. Dalam aspek disiplin ilmu, penekanan Geertz kepada aspek antropologi iaitu kemanusiaan dan sistem budayanya mempertontonkan gubahan semula yang kreatif terhadap gagasan Ibn Khaldun yang lebih cenderung untuk diklasifikasikan dalam gugusan sosiologi dan politik. Sepertimana Ibn Khaldun, pendekatan Geertz turut mementingkan elemen emperikal dan sistematikal sehingga telah memberi anjakan pendekatan dan menyedarkan para pengkaji akan peri pentingnya aspek praktikal agama untuk diberi perhatian dalam menilai sebarang isu dan tema yang dikaji mengenai agama. Walaupun seolah-olah Geertz mengabaikan doktrin dan konsep lantaran perhatian beratnya kepada unsur praktikal, namun praktik keagamaan adalah secara langsung menonjolkan gambaran realistik mengenai kepercayaan doktrinal dan pegangan konseptual dalam sesuatu agama yang dilihat sebagai simbolsimbol yang mewujudkan satu sistem yang dipanggil sebagai agama.

\section{References}

Banton, M. (ed.). 1969. Anthropological Approaches to the Study of Religion. Association of Social Anthropologists of the Commonwealth (A.S.A.) Monographs. Vol. 3., 3rd ed. London: Tavistock Publications Ltd.

Cragg, K. 2001. Counsels in Contemporary Islam. n.p.: n.p.

EMuseum. 2012. Anthropological Theories. http://www.mnsu.edu/emuseum/cultural/ anthropology/theories.html [23 January 2012].

al-Faruqi, Ismail Raji. 1967. Science and traditional values in Islamic society. Zygon 2: 231246.

Geertz, C. 1956. The Development of Javanese Economy: a Socio-Cultural Approach. Cambridge: Center for International Studies.

Geertz, C. 1958. Ethos, world view and the analysis of sacred symbol. The Antioch Review 58: 421-437.

Geertz, C. 1960. The Religion of Java. London : The Free Press of Glencoe.

Geertz, C. 1962. The growth of culture and the evolution of mind. In J. Scher (ed.). Theories of the Mind, pp. 713-740. New York: The Free Press..

Geertz, C. 1963. Agricultural Involution: The Processes of Ecological Change in Indonesia. Berkeley : University of California Press.

Geertz, C. 1964. Ideology as a cultural system. In D. Apter (ed.). Ideology and Discontent, pp. 47-76. New York: The Free Press.

Geertz, C. 1964a. Internal conversion in contemporary Bali. In J. Bastin \& R. Roolvink (ed.). Malayan and Indonesian Studies, pp. 282-302. Oxford: Oxford University Press..

Geertz, C. 1965. The Social History of an Indonesian Town. Cambridge n.p. pp. 119-208.

Geertz, C.1966. Religion as a cultural system. In M. Banton (ed.). Anthropological Approaches to the Study of Religion, pp. 204-215. London: n.p.

Geertz, C. 1966a. Person, Time and Conduct in Bali. n.p.: New Haven.

Geertz, C. 1966b. The impact of the concept of culture on the concept of man. In J. Platt (ed.). New Views of the Nature of Man. Chicago: n.p.

Geertz, C. 1968. Islam Observed: Religious Development in Morocco and Indonesia. Chicago : The University of Chicago Press. 
Geertz, C. 1969. Religion as a cultural system. In Michael Banton (ed.). Anthropological Approaches to the Study of Religion. Association of Social Anthropologists of the Commonwealth (A.S.A.), pp. 1-46. Monographs Vol. 3. 3rd ed. London: Tavistock Publications Limited.

Geertz, C. 1973. The Interpretation of Cultures. New York: Basic Books.

Geertz, C. 1980. Negara: the Theater State in Nnineteenth-century Bali. n.p.: n.p.

Geertz, C. 1981. Abangan, Santri, Priyayi dalam Masyarakat Jawa (The Religion of Java). Transl. Aswab Mahasin, Sunt. Bur Rasuanto. Jakarta: PT Dunia Pustaka Jaya.

Geertz, C. 1982. Islam yang Saya Amati: Perkembangan di Maroko dan Indonesia. Transl. Hasan Basari. Indonesia: Yayasan Ilmu-ilmu Sosial.

Inglis, Fred. 1999. Clifford Geertz: Culture, Custom and Ethics. n.p.: n.p.

McIntyre, A. (ed.). 1957. Metaphysical Beliefs. London : SCM Press.

Pick, R. 2012. Clifford Geertz. http://www.mnsu.edu/emuseum/information/biography /fghij/geertz_clifford.html [23 January 2012].

Roebuckclasses. 2012. Clifford Geertz. http://www.roebuckclasses.com/people/thinkers/ geertz.htm [23 January 2012].

Shop4Author. 2012. Top Selling Products for Clifford Geertz. http://www.shop4author.com/ Clifford\%20Geertz [28 January 2012].

Taufik Abdullah. 1982. C. Geertz dan agama sebagai sasaran studi antroplogi: sekadar pengenalan. In Clifford Geertz. Islam Yang Saya Amati: Perkembangan di Maroko dan Indonesia. Trans. by Hasan Basari. pp. i-xvi. Indonesia : Yayasan Ilmu-ilmu Sosial.

Thirteen. 2012. Clifford Geertz. http://www.thirteen.org/bigideas/geertz.html [28 January 2012]. 